\title{
EFFECT OF UV IRRADIATION ON MECHANICAL AND MORPHOLOGICAL PROPERTIES OF NATURAL AND SYNTHETIC FABRIC BEFORE AND AFTER NANO-TIO ${ }_{2}$ PADDING
}

\author{
J. Wiener ${ }^{1}$, A. Chládová1, S.Shahidii ${ }^{2}$, ,L. Peterová \\ ${ }^{1}$ Technical university of Liberec, Liberec, Studentská 2, 461 17, Czech Republic \\ ${ }^{2}$ Young Researchers and Elite Club, Arak Branch, Islamic Azad University, Arak, Iran \\ E-mail: sh-shahidi@iau-arak.ac.ir
}

\begin{abstract}
:
In this study, the effect of UV irradiation on mechanical properties of both natural and synthetic fabrics is investigated. Also the UV degradation of fabrics before and after $\mathrm{TiO}_{2}$ padding is studied. Cotton is used as natural fabric, and polyester, polypropylene, and polyamide were used as synthetic fabrics. After deposition with $\mathrm{TiO}_{2}$, prepared samples were irradiated by different dosage of UV light and the changes in fiber surface and the adhesion of nanoparticles is tested. The scanning electron microscopy, elemental analyses of Ti, and other methods were used. In some cases, the effect of stabilization of nanoparticles on fibers by UV light was realized. Reasons of this stabilization are the surface changes of polymer fibers-increase in surface roughness and oxidation of surface.
\end{abstract}

\section{Keywords:}

$\mathrm{TiO}_{2}$, cotton, polyester, polyamide, polypropylene, fibers

\section{Introduction}

Photocatalysis is a perspective process in many applications, such as waste water treatment, antibacterial treatments, superhydrophilization, and air decontamination [1-4]. In these processes, we need catalyst such as $\mathrm{TiO}_{2}$ stabilized on a holder. One of the interesting holders of nanoparticles are porous structures based on textile fibers-these structures have large surface area, are mechanically stable, and have liquors and gases that can easy penetrate through these structures [5].

Very recent studies have discussed the application of nanosized $\mathrm{TiO}_{2}$ in textile finishing, using the sol-gel technique, to impart effective protection against UV radiation and bacteria, stain resistance, deodorization, as well as self-cleaning because of its photocatalytic activity [6-15].

Using titanium dioxide $\left(\mathrm{TiO}_{2}\right)$ or nano- $\mathrm{TiO}_{2}$ as a catalyst or cocatalyst to improve the crease recovery property has been found to be feasible [16-19]. Titanium dioxide is added as a cocatalyst to enhance the finishing performance and minimize the side effect.

The conditions suitable for the catalyst to work properly are essential. The effect of the size of catalyst, which is known as "size effect," is an important characteristic for recognizing the fundamental catalytic properties. Ultra-fine catalyst is often more active as compared to larger ones probably because of their high surface area. Therefore, small catalytic particle size can enhance the chemical reactivity.

Stabilization of $\mathrm{TiO}_{2}$ on the surfaces can be based on sol-gel method [20-24]. Photocatalysis is photochemical reaction. The acceleration of this reaction is escorted by the presence of catalyzer. Photochemical reaction is inviting absorption of lights by materials whose molecules that absorbed energy are broken up to radicals, ions, or atoms [18]. Basic principle of photocatalyses is the transformation of UV light energy to chemical energy to form radicals and similar unstable chemical structures. The hydroxyl radicals $(\mathrm{OH})$ and superoxide radical anions $\left(\mathrm{O}^{2-}\right)$ are supposed to be the primary oxidizing species in the photocatalytic oxidation processes [16,17]. Useful photocatalysts (such as $\mathrm{TiO}_{2}$ ) are effective UV absorbers. [25]

In many papers, we can find lot of techniques on how to stabilize nanoparticles on textile fibers based generally on the application of supporting chemicals to protect the surface of polymeric fibers and increase the adhesion of nanoparticles on fiber surface.

The most important properties of textile treatments are durability and washing fastness. Although the nanoparticles can provide high durability for treated fabrics with respect to conventional materials, many researchers have tried to improve wash fastness by means of some binders and spacers or other methods. In this research work, the effect of UV on mechanical properties of both natural and synthetic fabric before and after $\mathrm{TiO}_{2}$ padding is investigated. Also the effect of UV on washing fastness of $\mathrm{TiO}_{2}$ on surface of fabrics is studied.

\section{Experimental}

\subsection{Materials and chemicals}

Aeroxide P25 Degussa (nano- $\mathrm{TiO}_{2}$ ) that contains $70 \%$ anatase and $30 \%$ rutile was used in this study. The mean diameter of the used nanoparticles was $21 \mathrm{~nm}$. Experiments were realized on textile samples described in Table 1 . These four fabrics 
represent the mostly used textiles in clothing industry, and they represent polymers with highest difference from chemical point of view. Cotton is a natural fiber based on cellulose, which in contact with liquid water intensively swells and open its internal structure because its nature is polar and hydrophilic. Other three fibers are synthetic and represent different levels of hydrophilicity: polyamide (PA) is hydrophilic and polypropylene (PP) is extremely hydrophobic. The samples were washed using $1 \mathrm{~g} \mathrm{I}^{-1}$ nonionic detergent (Triton X-100 solution from Sigma-Aldrich)and $2 \mathrm{~g} \mathrm{l}^{-1}$ of sodium carbonate at $50{ }^{\circ} \mathrm{C}$ for 30 min before starting the experiments.

\subsection{Deposition of $\mathrm{TiO}_{2}$ nanoparticles}

Nanoparticles of $\mathrm{TiO}_{2}$ were suspended in water system by ultrasound homogenizer Sonopuls HD 3200 (Bandelin Electronics, Germany). Final concentration of $\mathrm{TiO}_{2}$ was $10 \mathrm{~g} \mathrm{l}^{-1}$.

Photocatalytic nanoparticles of $\mathrm{TiO}_{2}$ were deposed on fiber surfaces by padding technology. Textile samples were immersed in above-described suspension of $\mathrm{TiO}_{2}$ nanoparticles, squeezed on padding machine with $70 \%$ of wet pickup, and dried. Squeezing was realized on pneumatic padding machine Mathis (Switzerland) at a pressure of $4 \mathrm{kN}$ with a velocity of $1 \mathrm{~m} / \mathrm{min}$. Drying of samples was realized in basic drying box at $110^{\circ} \mathrm{C}$ for $20 \mathrm{~min}$. Before irradiation, textile samples were protected against undefined UV light.

\subsection{UV irradiation}

In this research, both nano- $\mathrm{TiO}_{2}$-treated and untreated samples were UV irradiated for up to $600 \mathrm{~min}$. UV light tubes (4_Philips TL 6W-F6 T5) were used. Intensity of UV light on the sample surface was $40.4 \mathrm{~mW} \mathrm{~cm}^{-2}$ of UVA and $4.1 \mathrm{~mW} \mathrm{~cm}^{-2}$ of UVB. Textile samples were cooled by air flow during UV irradiation. Water is one of the necessary components of photocatalysis. So observing the humidity of sample during the UV irradiation is necessary. In this study, "wet experiment" (air humidity is $95 \%$ and pick up $200 \%$ of the weight of textile sample) was used. Water was deposed by spraying of distilled water. Experiments were realized in closed PP box with special holder of textile sample (Fig. 1).

\subsection{Characterization methods}

Mechanical properties of textile samples were measured on laboratory tensile tester Labtest 2.05. Yarns separated from the fabric were analyzed by the velocity of holder, $250 \mathrm{~mm} / \mathrm{min}$. Testing length was $200 \mathrm{~mm}$. Samples were acclimatized before irradiation at relative air humidity of $65 \%$. All presented values are calculated as the average value from the 20 measurements.

Quantity of $\mathrm{Ti}$ on textile samples was estimated by X-ray fluorescence (XRF). XRF is based on the emission of characteristic secondary or fluorescent $\mathrm{X}$-rays from a material

Table 1: Description of used textiles

\begin{tabular}{|c|c|c|c|c|c|c|}
\hline Fabric & Abbreviation & $\begin{array}{c}\text { Areal density } \\
\left(\mathbf{g ~ m} \mathbf{~}^{2}\right)\end{array}$ & Structure & $\begin{array}{c}\text { Warp set per } \\
\mathbf{1 0} \mathbf{~ c m}\end{array}$ & $\begin{array}{c}\text { Weft set per } \\
\mathbf{1 0} \mathbf{~ c m}\end{array}$ & $\begin{array}{c}\text { Fiber diameter } \\
(\boldsymbol{\mu m})\end{array}$ \\
\hline Cotton & CO & 115 & Plain wave & 280 & $\begin{array}{c}10 \text { (noncircular } \\
\text { cross section) }\end{array}$ \\
\hline Polyester & PES & 120 & Plain wave & 220 & 190 & 22 \\
\hline Polyamide 6 & PA6 & 80 & Plain wave & 340 & 260 & 25 \\
\hline Polypropylene & PP & 172 & Plain wave & 90 & 90 & $\begin{array}{c}15 \text { (noncircular } \\
\text { cross section) }\end{array}$ \\
\hline
\end{tabular}

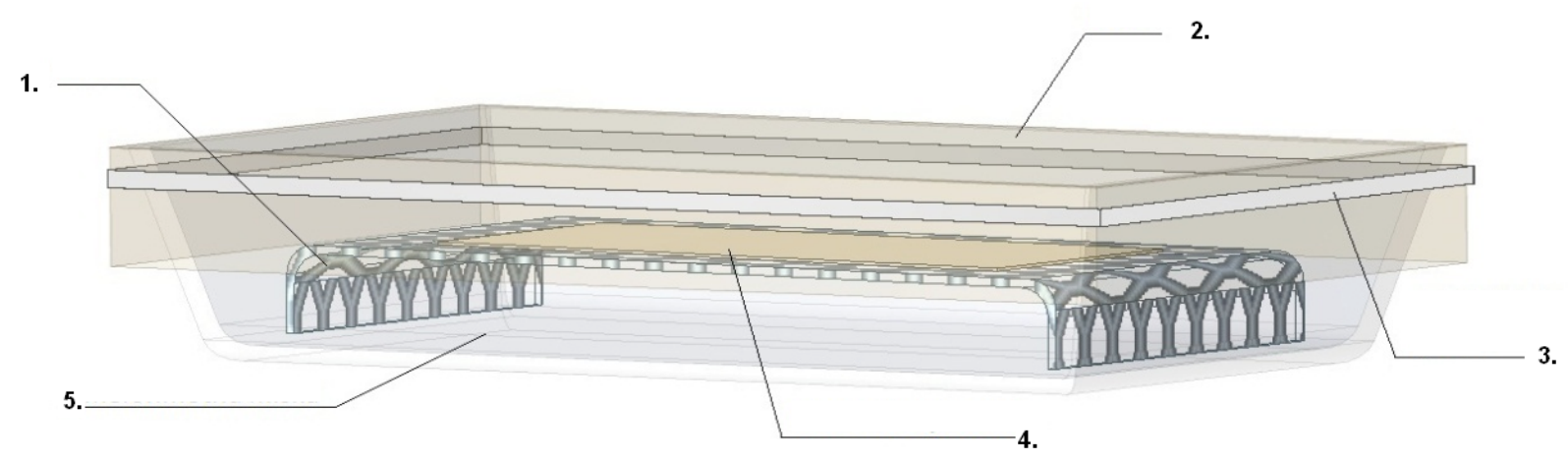

Figure 1: Description of the experimental arrangement-(1) metal mesh holder of sample, (2) transparent foil, (3) flexible holder, (4) irradiating sample, and (5) polypropylene box 
that has been excited by bombarding with high-energy X-rays. Used XRF analyzer "ElvaX" is a desktop energy-dispersive $X$-ray fluorescence (EDXRF) analyzer spectrometer that does not require liquid nitrogen cooling for storage and use. Surface of samples was visualized by scanning electron microscopy on the instrument Tescan VEGA TS 5130MM after gold layer deposition.

\section{Results and discussion}

\subsection{Tensile strength}

The results related to tensile strength of samples under different time of UV exposure are shown in Figs. 2-5. In all cases, we can see similar trend on samples with and without photocatalytic $\mathrm{TiO}_{2}$ nanoparticles. Explanation of results is complicated because tensile strength is based not only on mechanical strength of fibers but also connected with the friction properties of fibers. The friction properties are influenced by deposition of $\mathrm{TiO}_{2}$ nanoparticles in textile structure. In case of cotton samples, the results show that the strength of sample with nano- $\mathrm{TiO}_{2}$ in both dry and wet cases is higher than the sample without $\mathrm{TiO}_{2}$. It shows that the existence of titanium dioxide causing the increase in the strength of cotton fabric. In shorter time of UV irradiation, the strength is high in wet condition, but by increasing the time of irradiation, the strength decreases. But the effect of UV irradiation is not significant in $b$ oth the cases.
For PP fabrics (Fig. 3), the UV irradiation causes the reduction of strength; however, it is not noticeable. The behavior of both $\mathrm{TiO}_{2}$ treated and untreated PP in wet condition is the same. In dry condition, the existence of nano- $\mathrm{TiO}_{2}$ causes less reduction in strength.

For polyester sample (Fig. 4), linear decrease in the strength during the UV irradiation is achieved. This dependence was observed on samples with and without nanoparticles of $\mathrm{TiO}_{2}$. In both dry and wet situations, this reduction is seen. The existence of nano- $\mathrm{TiO}_{2}$ causes the reduction of strength in polyester samples. Polyester fibers has compact structure, and during the melt spinning, $\mathrm{TiO}_{2}$ particles is added for reducing the lustre properties. In this research by adding nano- $\mathrm{TiO}_{2}$, the extra amounts of $\mathrm{TiO}_{2}$ are added, and these extra amounts cause the reduction in strength of the polyester samples.

In the case of PA fibers (Fig. 5), the behavior is similar to that of cotton. By UV irradiation for up to $350 \mathrm{~min}$, the strength increases. By increasing the time of irradiation to more than $500 \mathrm{~min}$, the strength reduces again. It should be mentioned that the strength of PA sample after UV irradiation for $600 \mathrm{~min}$ is more than that of the sample before irradiation. It means that UV irradiation in case of PA causes increase in strength. For $\mathrm{TiO}_{2}$-treated $\mathrm{PA}$, the existence of $\mathrm{TiO}_{2}$ causes increase in the strength of sample before UV irradiation as compared with untreated PA. By UV irradiation for up to $350 \mathrm{~min}$, the strength of sample increases. However, by increasing the time of irradiation for more than $350 \mathrm{~min}$, the strength is decreased.

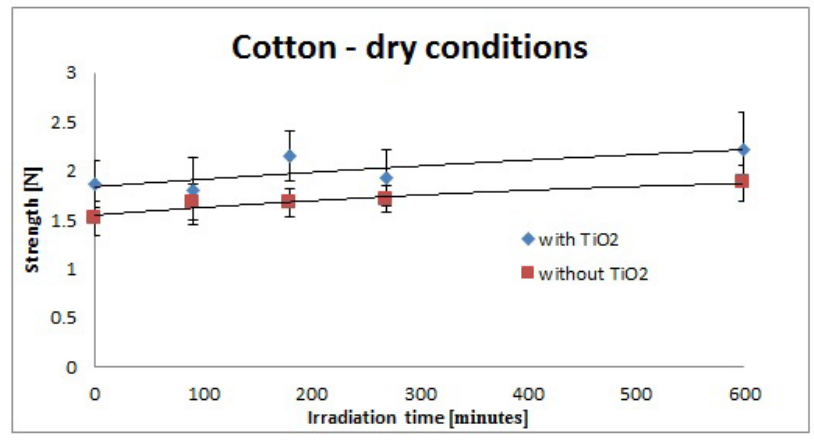

(a)

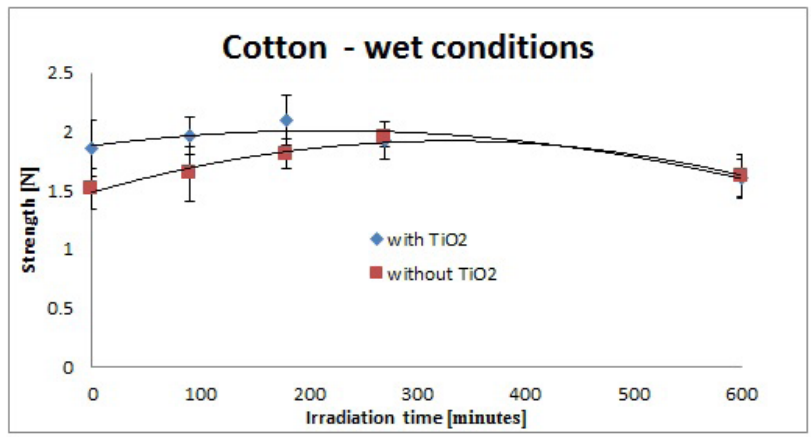

(b)

Figure 2: Tensile strenght of cotton fibers as a functuon of irradiatrion time (with and without $\mathrm{TiO}_{2}$ ): (a) dry conditions and (b) wet conditions

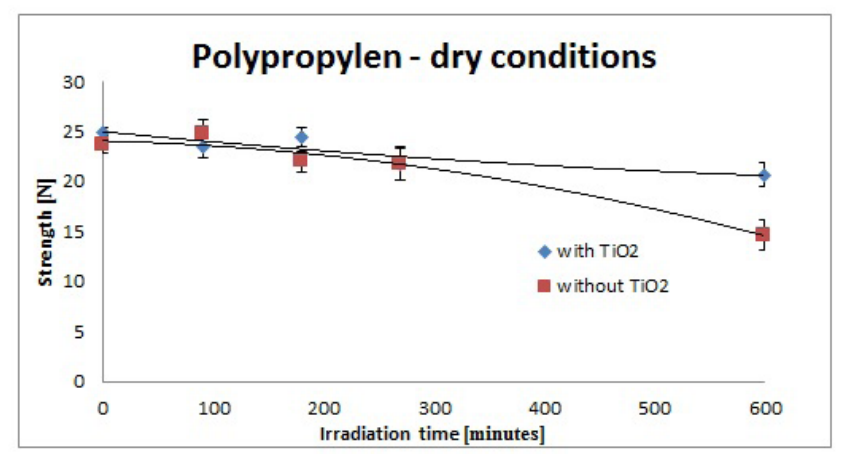

(a)

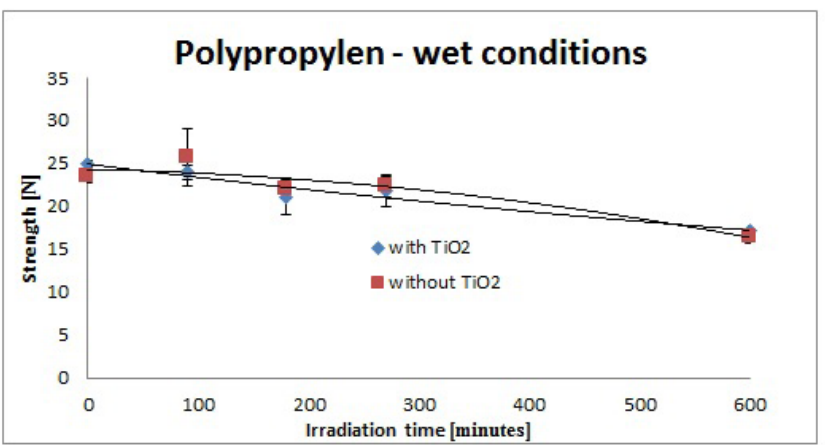

(b)

Figure 3: Tensile strenght of polypropylene fibers as a functuon of irradiatrion time (with and without $\mathrm{TiO}_{2}$ ): (a) dry conditions and (b) wet conditions 


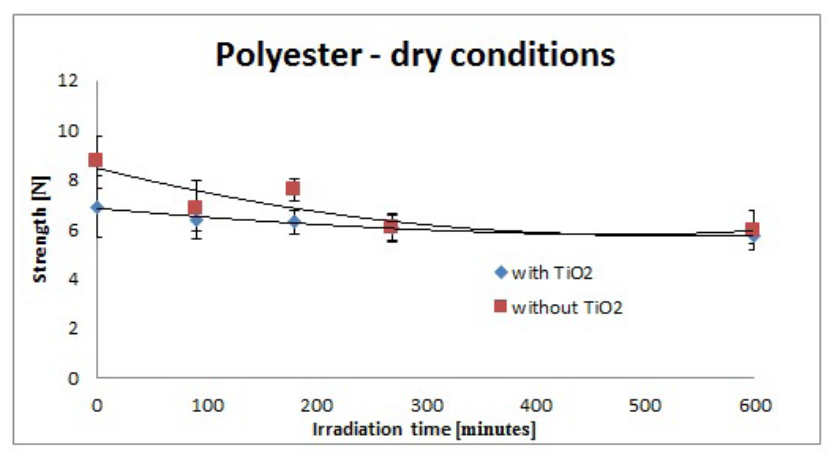

(a)

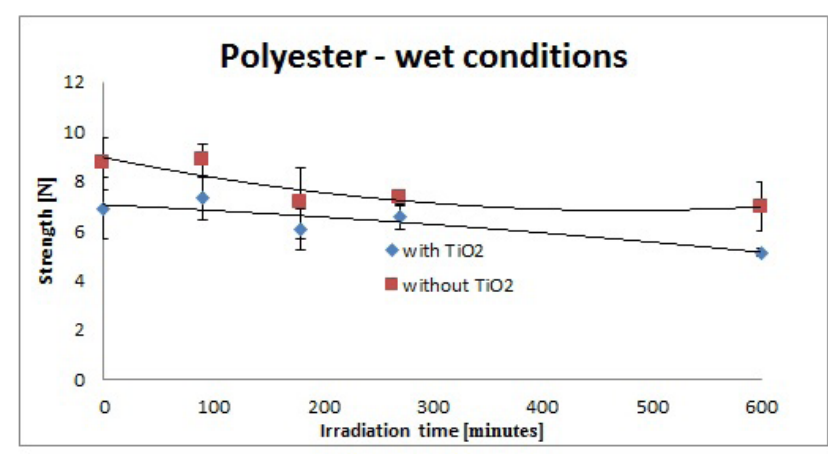

(b)

Figure 4: Tensile strenght of polyester fibres as a functuon of irradiatrion time (with and without $\mathrm{TiO}_{2}$ ): (a) dry conditions and (b) wet conditions

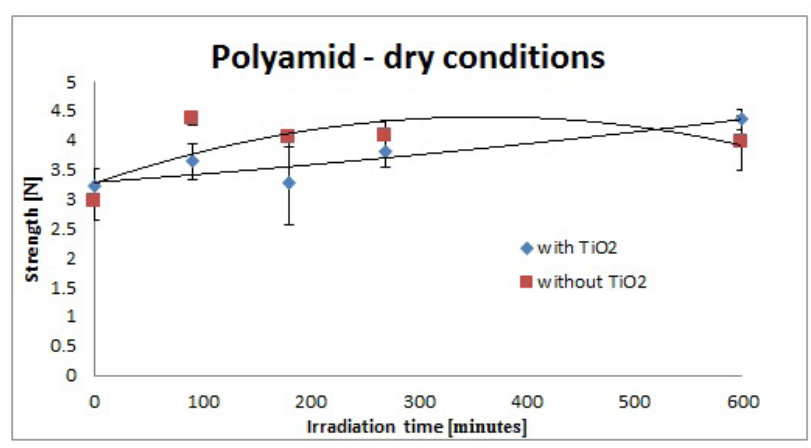

(a)

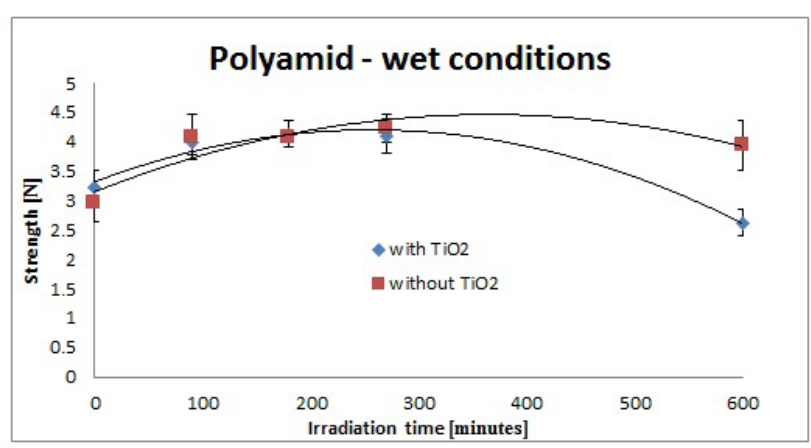

(b)

Figure 5: Tensile strenght of polyamide fibers as a functuon of irradiatrion time (with and without $\mathrm{TiO}_{2}$ ): (a) dry conditions and (b) wet conditions

It is seen that by UV irradiation for $600 \mathrm{~min}$, the strength of sample is similar to the sample without irradiation.

For PA sample, it should be mentioned that the hydrophilic nature of fiber helps absorb more amounts of $\mathrm{TiO}_{2}$. First in short time of UV irradiation or without irradiation, the strength of the sample increases as compared with the sample without $\mathrm{TiO}_{2}$. By increasing the time of irradiation to more than $200 \mathrm{~min}$, the strength of the sample decreases significantly. This reduction in strength is caused by photocatalytic activity of nano- $\mathrm{TiO}_{2}$. The presence of nano- $\mathrm{TiO}_{2}$ helps in the transformation of UV light energy to chemical energy to the form of radicals and similar unstable chemical structures. The hydroxyl radicals $(\mathrm{OH})$ and superoxide radical anions $\left(\mathrm{O}^{2-}\right)$ are supposed to be the primary oxidizing species in the photocatalytic oxidation processes. In dry condition, the existence of $\mathrm{TiO}_{2}$ causes increase in the strength of PA fabrics. The effect of UV and nano- $\mathrm{TiO}_{2}$ on PA samples is similar to that of cotton. It can be because of the hydrophilic nature of both the samples.

\subsection{Elemental analyses, XRF}

For quantification of adhesion of $\mathrm{TiO}_{2}$ nanoparticles to the fiber surface, elemental analysis (XRF) was used. The basic idea was if the adhesion is low, we can remove all $\mathrm{TiO}_{2}$ nanoparticles by washing.
Both UV-irradiated and nonirradiated samples were washed in nonionic surfactant $\left(5 \mathrm{~min}, 60^{\circ} \mathrm{C}, 1: 100,2 \mathrm{~g} \mathrm{l}^{-1}\right)$ in stirred metal beaker.

The washed samples were analyzed, and the XRF values are compared with the initial results of XRF, and the elimination of $\mathrm{Ti}$ from sample in percentage was calculated. Calculated results are shown in Fig. 6.

The results show that without any irradiation, the highest adhesion of nanoparticles is for cotton and the lowest is related to PA fibers.

All synthetic fibers have the similar behavior. UV radiation stabilized the nanoparticles of $\mathrm{TiO}_{2}$ on fiber surface. This effect is extremely effective on PA, where less amount of $\mathrm{TiO}_{2}$ is removed from samples after $600 \mathrm{~min}$ of UV radiation. In case of cotton, the opposite results were achieved. After UV irradiation, more amounts of $\mathrm{TiO}_{2}$ are removed from the surface of irradiated fibers. It may be due to the increase in the evenness of cotton fibers after UV irradiation.

\subsection{Electron microscopy}

Electron microscopy was used for the evaluation of fiber surface-visualization of $\mathrm{TiO}_{2}$ particles and surface roughness. 


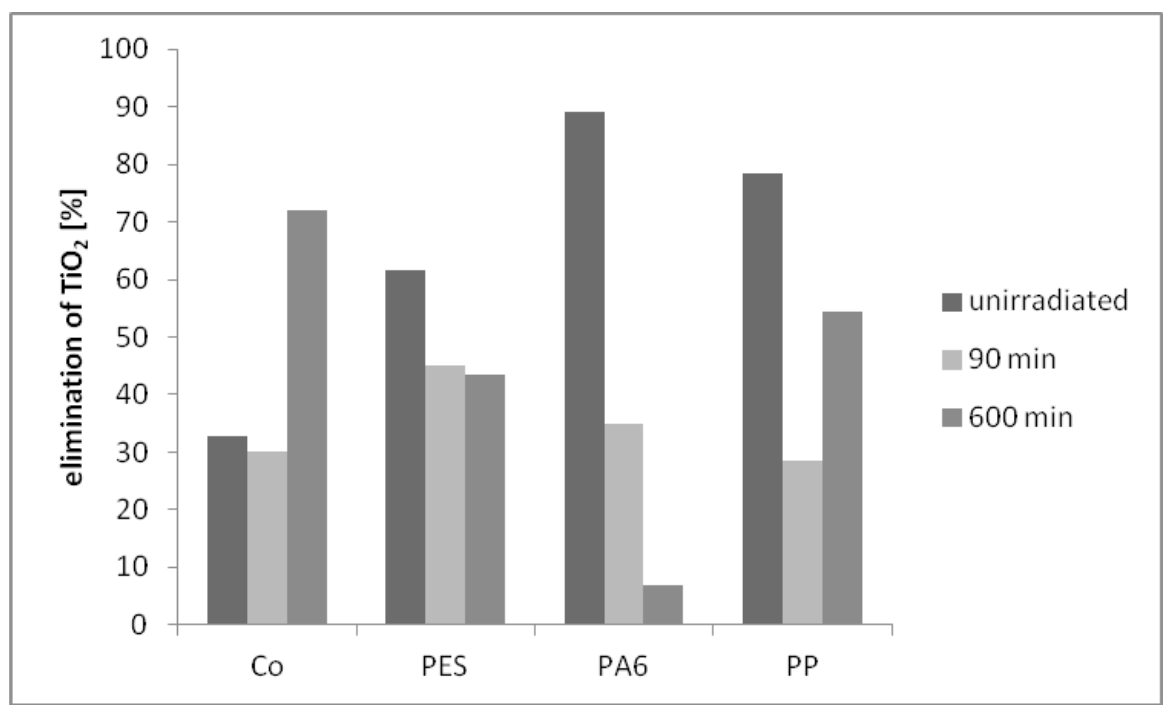

Figure 6: Quantity of $\mathrm{TiO}_{2}$ removed by washing from all used fibers, comparison of original and UV-irradiated samples (90 and $\left.600 \mathrm{~min}\right)$

On cotton fibers, we can see (Figs. 7 and 8 ) lots of $\mathrm{TiO}_{2}$ nanoparticles and the roughness of the cotton fibers is not changed by UV irradiation. After washing UV-irradiated cotton, less amounts of $\mathrm{TiO}_{2}$ remain on the surface, and these results confirm the achieved results by XRF.

In case of polyester, it is also visible that after UV irradiation, more amounts of nano- $\mathrm{TiO}_{2}$ is attached on the surface of the fibers (Figs. 9 and 10).

(a)
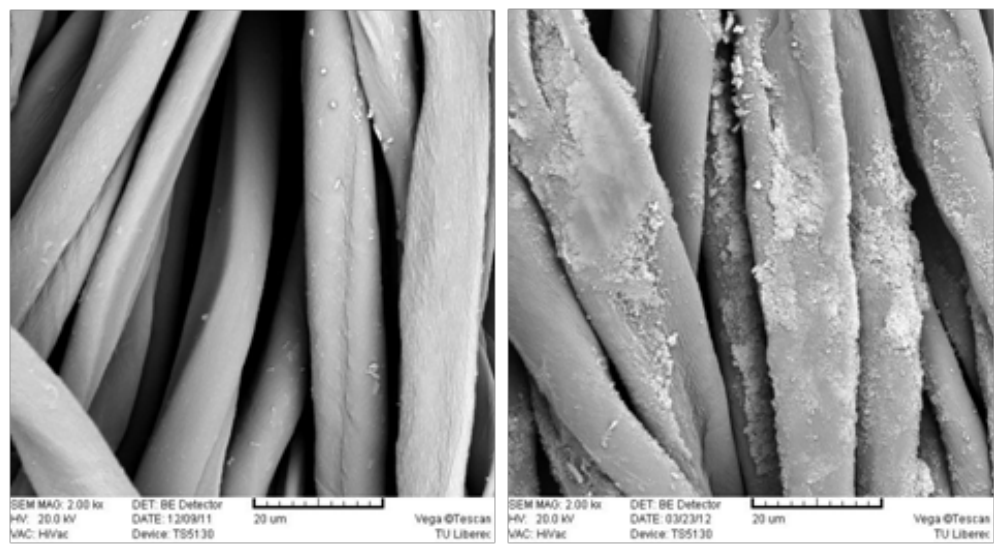

(b)

On the surface of PP and PA fibers (Figs. 11-14), we can see relatively low quantity of $\mathrm{TiO}_{2}$ nanoparticles. It is because of even surface of fibers as compare with cotton and polyester fibers.

After UV irradiation, some pores are created on the surface of fibers. These small roughness increase the adhesion of $\mathrm{TiO}_{2}$ particles on the surface.

(b)

(c)

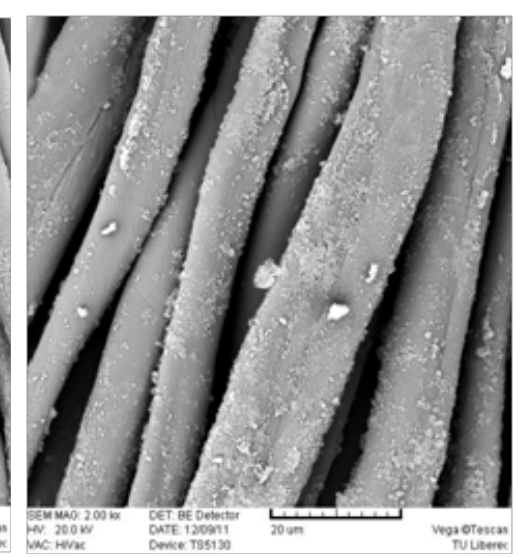

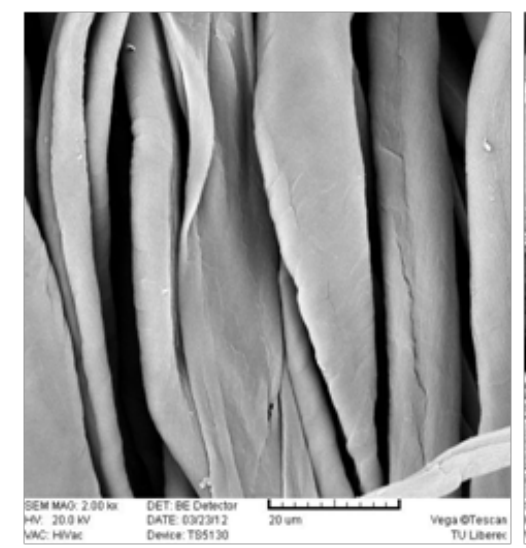

(b)

(a)

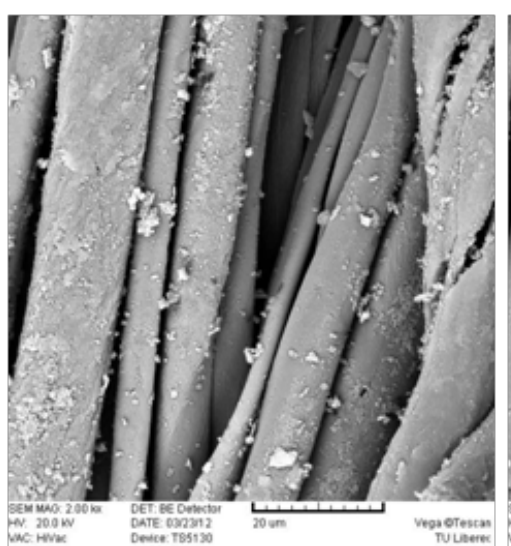

(c)

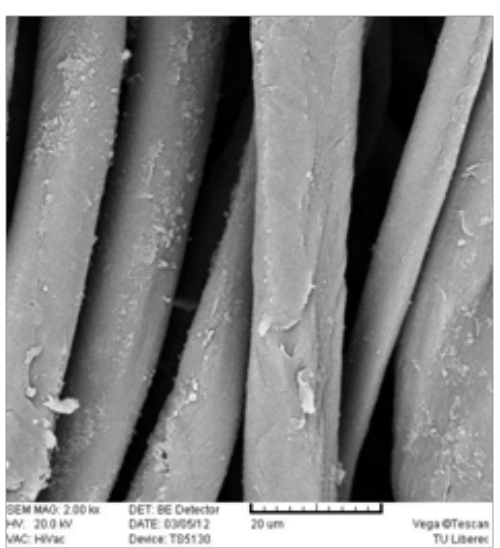

Figure 8: Cotton fibers after 600 min of UV irradiation: (a) sample without $\mathrm{TiO}_{2}$, (b) sample with $\mathrm{TiO}_{2}$ before washing, and (c) sample with $\mathrm{TiO}_{2}$ after washing 
(a)

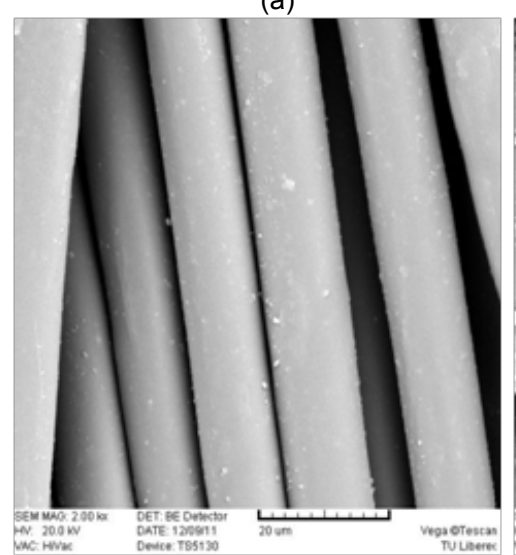

(b)

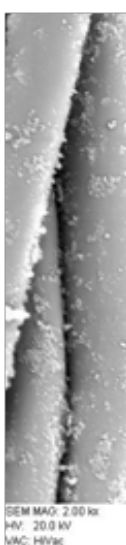

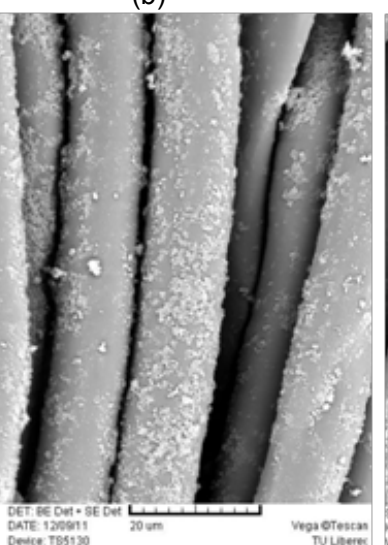

(c)

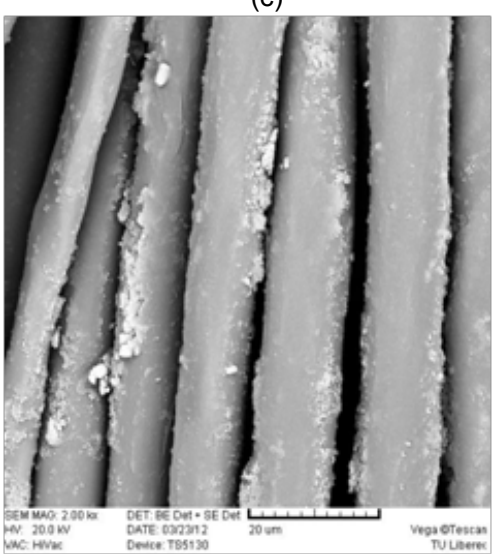

Figure 9: Polyester fibers without UV irradiation: (a) sample without $\mathrm{TiO}_{2}$, (b) sample with $\mathrm{TiO}_{2}$ before washing, and (c) sample with $\mathrm{TiO}_{2}$ after washing

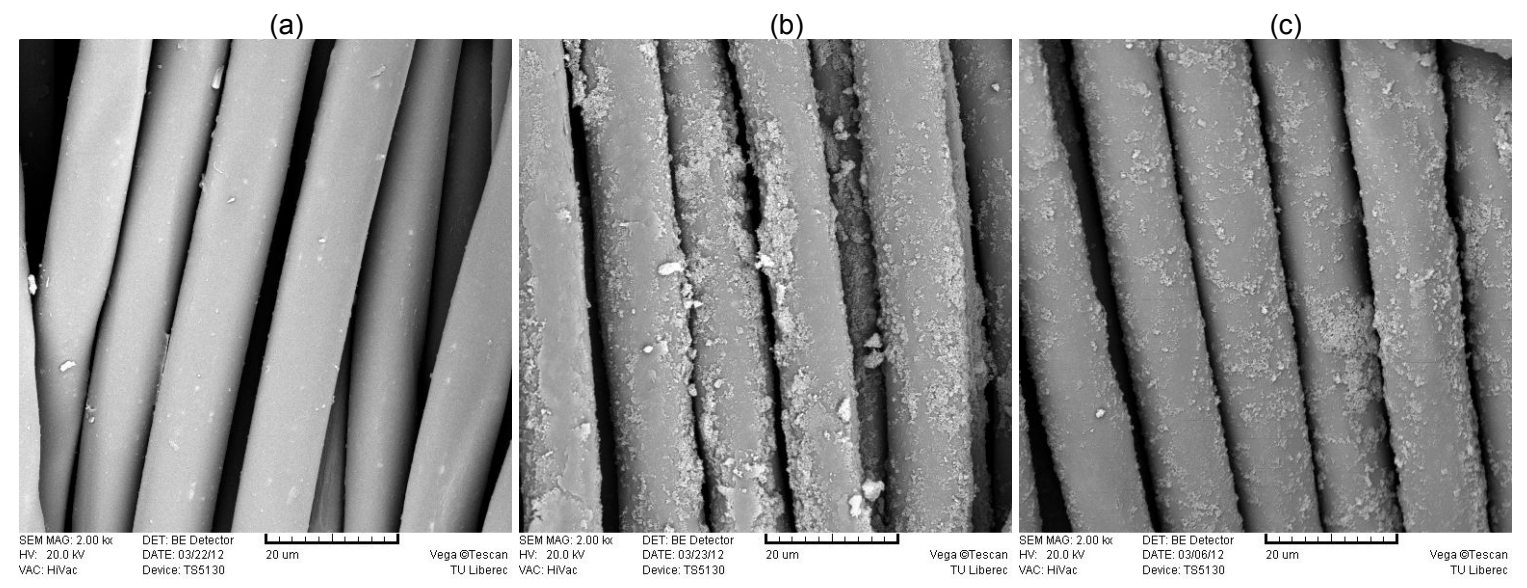

Figure 10: Polyester fibers after 600 min of UV irradiation: (a) sample without $\mathrm{TiO}_{2}$, (b) sample with $\mathrm{TiO}_{2}$ before washing, and (c) sample with $\mathrm{TiO}_{2}$ after washing

$\mathrm{TiO}_{2}$ nanoparticles damaged the surface of fibers. It does not have direct influence on tensile strength of fibers, but influences the friction and the stability of $\mathrm{TiO}_{2}$ nanoparticles on the surface of fibers. Especially, in the case of PA and PP fibers, we observed an increase in the surface roughness based on the local decomposition of polymer surface by photocatalysis (Fig. 15). This increase in roughness is connected with interesting increase in the stability of $\mathrm{TiO}_{2}$ nanoparticles on the fiber surface.

\section{Conclusions}

In this research work, the effect of UV on mechanical properties of both natural and synthetic fabric before and after $\mathrm{TiO}_{2}$ padding has been investigated. Cotton, PA 6, polyester, and PP fibers were treated by UV light with and without $\mathrm{TiO}_{2}$ particles. The samples were analyzed by tensile strength measurement, washing tests, elemental analyses, and scanning electron microscopy. (a)

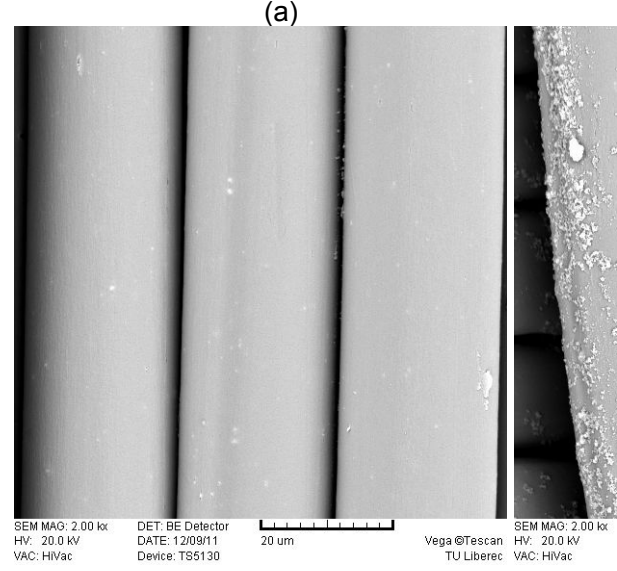

(b)

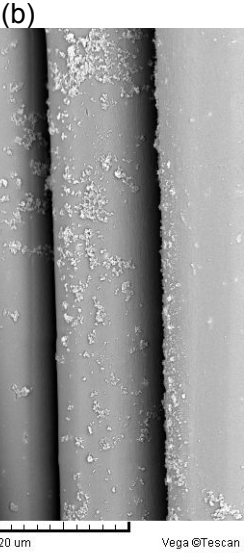

(c)

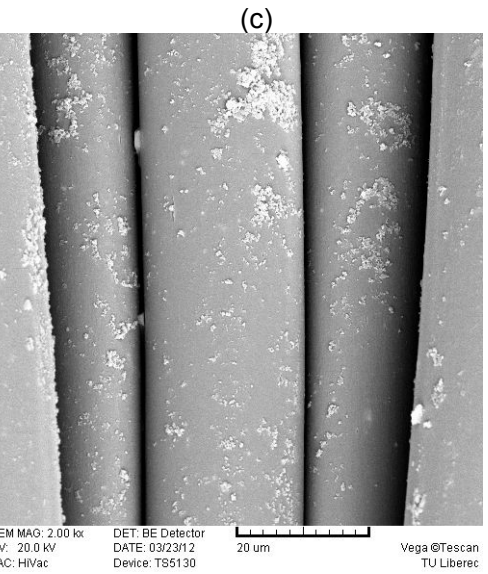

Figure 11: Polyamide fibers without UV irradiation: (a) sample without $\mathrm{TiO}_{2}$, (b) sample with $\mathrm{TiO}_{2}$ before washing, and (c) sample with $\mathrm{TiO}_{2}$ after washing 


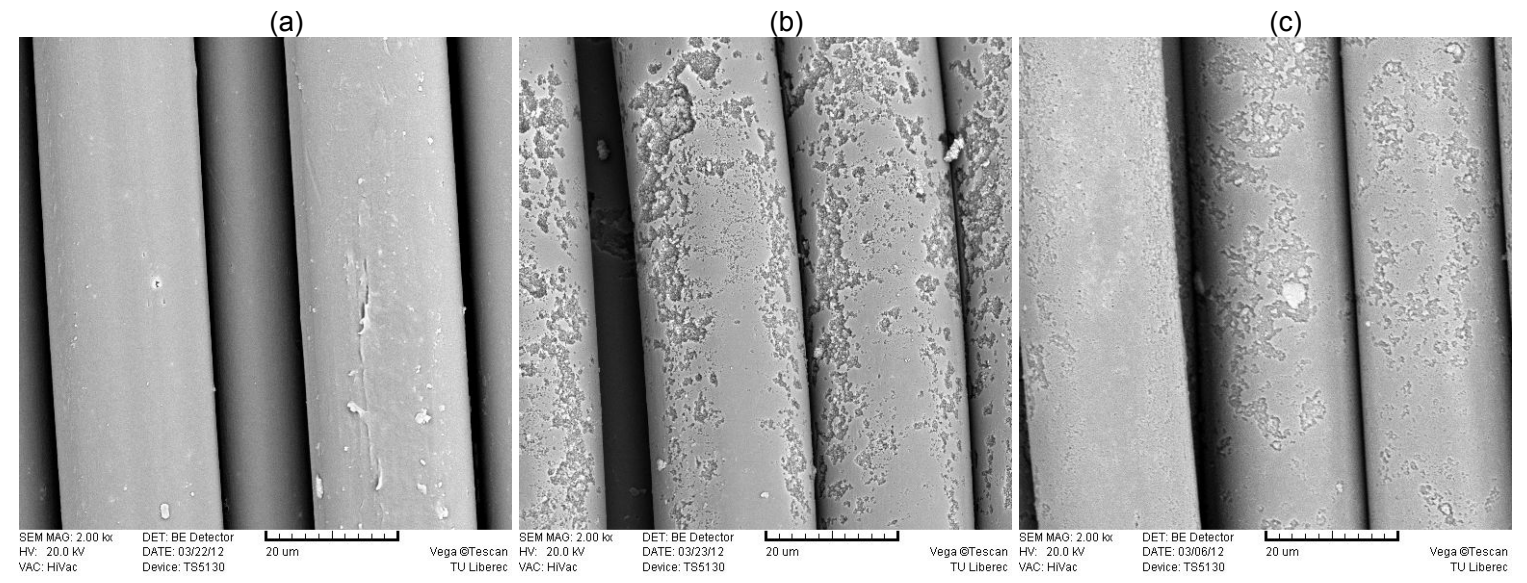

Figure 12: Polyamide fibers after 600 min of UV irradiation: (a) sample without $\mathrm{TiO}_{2}$, (b) sample with $\mathrm{TiO}_{2}$ before washing, and (c) sample with $\mathrm{TiO}_{2}$ after washing

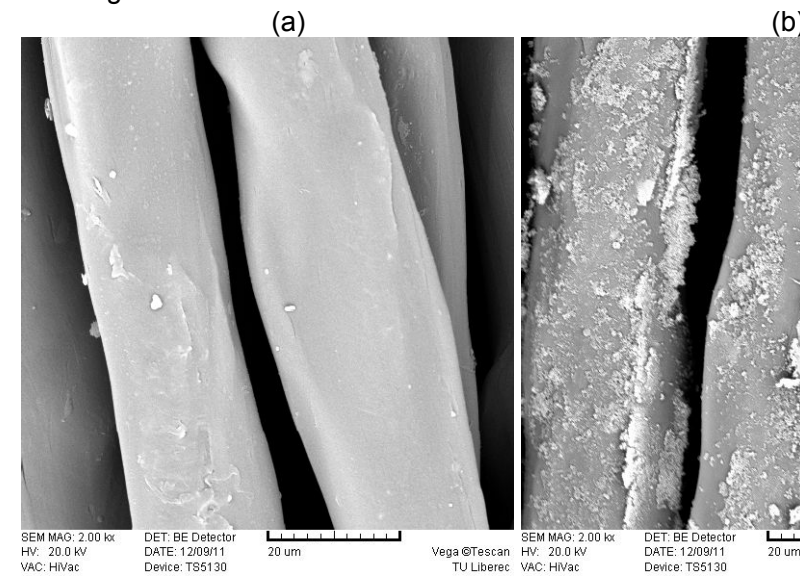

(b)

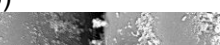

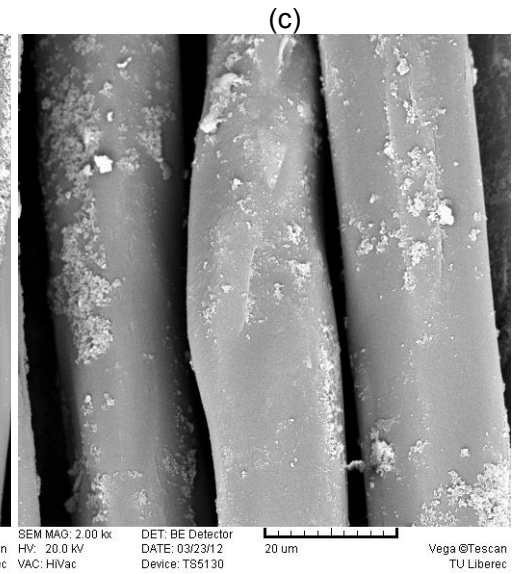

Figure 13: Polypropylene fibers without UV irradiation: (a) sample without $\mathrm{TiO}_{2}$, (b) sample with $\mathrm{TiO}_{2}$ before washing, and (c) with $\mathrm{TiO}_{2}$ after washing

(a)

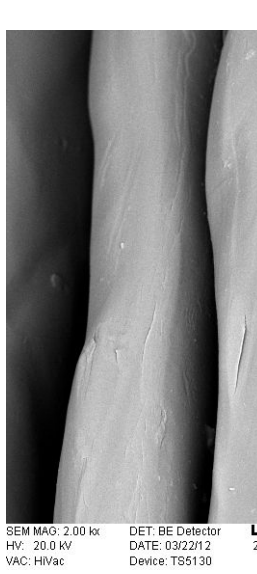

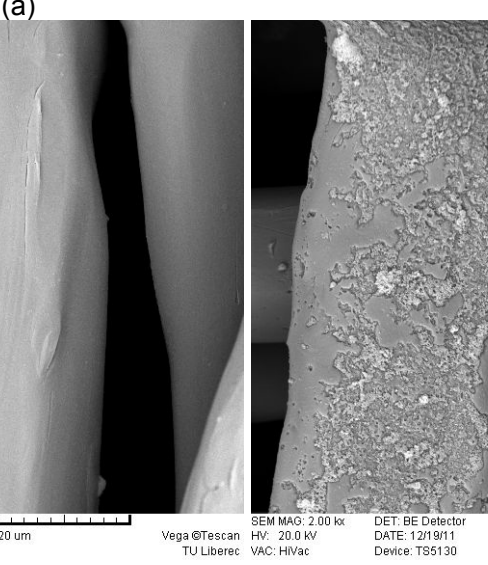

(b) (c)

(c)

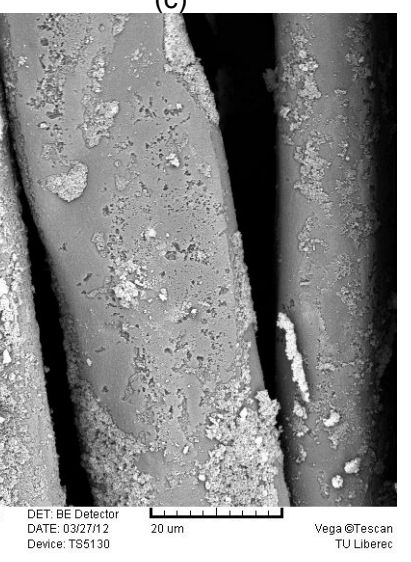

Figure 14: Polypropylene fibers after 600 min of UV irradiation: (a) sample without $\mathrm{TiO}_{2}$, (b) sample with $\mathrm{TiO}_{2}$ before washing, and (c) sample with $\mathrm{TiO}_{2}$ after washing

The observed behavior of textile structures can be connected with the basic knowledge of photocatalysis and UV damage of polymers. By irradiation of polymer fibers, the UV light penetrate deeply to the polymer mass (Fig. 15a), and the polymer composition is changed by chemical reaction, and consequently, the mechanical strength of fibers is reduced. By adding nanoparticles of $\mathrm{TiO}_{2}$ on the surface of fibers, the UV light is effectively absorbed at the surface (Fig. 15b) and the UV light energy is transformed into chemical energy on the fiber surface. This change in UV light flow increases the damage of fiber surface and protects the mass of fiber. If the deposition of
$\mathrm{TiO}_{2}$ particles is not even on the fiber surface (in some places, the fiber surface will be without $\mathrm{TiO}_{2}$ nanoparticles), then the mass of polymer is not enough protected against UV light and mechanical properties of fabrics such as tensile strength is decreased. The observed changes in mechanical properties are, in our cases, based on the damage of fibers by UV light and by the change in friction properties of fibers. In case of cotton samples, UV irradiation do not play any role in reducing the strength of samples. Also the existence of nano- $\mathrm{TiO}_{2}$ causes the strength to increase; however, it is not noticeable. The reason can be because of uneven structure of cotton fibers. 
(a)

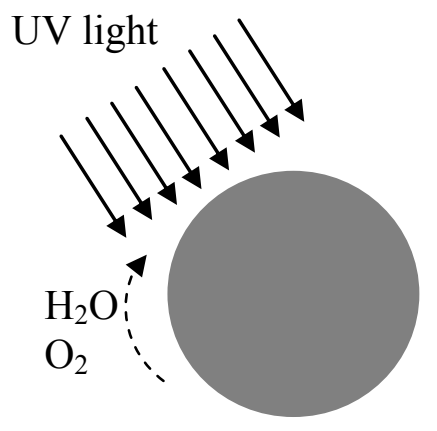

(b)

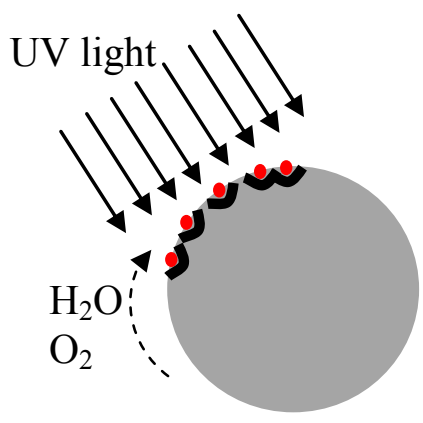

Figure 15: Damage of polymer fiber by UV irradiation (cross section): (a) without $\mathrm{TiO}_{2}$ and (b) with $\mathrm{TiO}_{2}$ particles

\section{Acknowledgment}

This study was supported by TAČR TA01010613-“Vodné nanodisperze pro funkčni povrchové úpravy" (Nanocover), Czech Republic.

\section{References}

[1] G. Buschle-Diller, S.H. Zeronian, Weathering and Photodegradation of Cellulose. Photochemistry of Lignocellulosic Materials, 14(1993)177-189

[2] D. Saravanan, UV protection textile materials. AUTEX Research Journal, 7(2007) 58-62

[3] M.Pouzar, M.Prušová,T.Cernohorsky,J.Wiener,T. Kratochvil,Analyses of $\mathrm{Ti}$ in textile stippled by $\mathrm{TiO} 2$ nanoparticle sol using double-pulse LIBS and ED XRF spectrometry, Journal of Applied Spectroscopy, 78(2011)673-679

[4] M. Prǔšová, J.Wiener, Application of LIBS method in analyses of carbon and titanium in textile structure, Textile research journal,82(2012) 1092-1098

[5] J.Wiener, S.Shahidi, M.M.Goba, Laser deposition of TiO2 nanoparticles on glass fabric, Optics \& Laser Technology, 45 (2012) 147-153

[6] Z. Liuxue, L. Peng, S. Zhixing, Photocatalysis anatase thin film coated PAN fibers prepared at low temperature, Materials Chemistry and Physics 98 (2006) 111-115

[7] A. Nazari, M. Montazer, A. Rashidi, M. Yazdanshenas , M. Anary-Abbasinejad, Nano TiO2 photo-catalyst and sodium hypophosphite for cross-linking cotton with poly carboxylic acids under UV and high temperature, Applied Catalysis A: General 371 (2009) 10-16

[8] K. Qi, X. Wang and J. H. Xin, Photocatalytic self-cleaning textiles based on nanocrystalline titanium dioxide, Textile Research Journal 81(1) 101-110

[9] T. Sakai, Y. Kuniyoshi, W. Aoki, S.Ezoe, T. Endo, Y. Hoshi, High-rate deposition of photocatalytic TiO2 films by oxygen plasma assist reactive evaporation method, Thin Solid Films 516 (2008) 5860-5863

[10] D. Mihailovic', Z. Šaponjic', M. Radoic 'ic', T. Radetic', P. Jovanc 'ic', J. Nedeljkovic' ,M. Radetic', Functionalization of polyester fabrics with alginates and TiO2 nanoparticles, Carbohydrate Polymers 79 (2010) 526-532

[11] W. A. Daoud, J. H. Xin, Y.H. Zhang, Surface functionalization of cellulose fibers with titanium dioxide nanoparticles and their combined bactericidal activities, Surface Science 599 (2005) 69-75
[12] Y. L. Lam, C. W. Kan, and C. W. M. Yuen, Effect of Concentration of Titanium Dioxide Acting as Catalyst or Co-catalyst on the Wrinkle-resistant Finishing of Cotton Fabric, Fibers and Polymers, 11(2010) 551-558

[13] Y. L. Lam, C. W. Kan, C. W. M. Yuen, and C. H. Au, Fabric Objective Measurement of the Plasma-treated Cotton Fabric Subjected to Wrinkle-resistant Finishing with BTCA and TiO2 System, Fibers and Polymers, 12 (2011) 626634

[14] C. Yang, G. L. Liang, K. M. Xu, P. Gao, B. Xu, Bactericidal functionalization of wrinkle-free fabrics via covalently bonding TiO-Ag nanoconjugates $J$ Mater Sci 44 (2009)1894-1901

[15] Z. Liuxue, W. Xiulian, L. Peng, S. Zhixing, Low temperature deposition of TiO2 thin films on polyvinylalcohol fibers with photocatalytical and antibacterial activities, Applied Surface Science 254 (2008) 1771-1774

[16]I. K. Konstantinou and T. A. Albanis, "TiO2-Assisted Photocatalytic Degradation of Azo Dyes in Aqueous Solution: Kinetic and Mechanistic Investigations," Applied Catalysis B: Environmental, 49(2004) 1-14.

[17]A. Fujishima, K. Hashimoto, T. Watanabe, TiO2 Photocatalysis, Fundamentals and Applications, BKC, Tokyo 1999.

[18] M.Kaneko, I.Okura, Photocatalysis (Scienceand Technology), Kodasha Ltd., Tokyo, 2002, ISBN4-06210615-9

[19] A.Masakazu, Kamat V. Prashant, Environmenttally Benign Photocatalysts. New York: Springer, 2010. ISBN 978-0387-48441-9

[20] Lćurkovic', D. Ljubas, H. Juretic', Photocatalytic decolourization kinetics of diazo dye Congo Red aqueous solution by UV/TiO2 nanoparticles, Reaction Kinetics, Mechanisms and Catalysis 99 (1) (2010) 201-208.

[21] Ling, C.M., Mohamed, A.R., Bhatia, S., Performance of photocatalytic reactors using immobilized TiO2 film for the degradation of phenol and methylene blue dye present in water stream, Chemosphere 57 (2004) 547- 554.

[22] Chládová, A., Wiener, J., Exnar, P., Špaldová, M.: Photocatalytic textiles prepared bysol-gel method, Vlákna a textil, 4 (2011) 9-15

[23] W.Feng, D. Nansheng and $H$. Helin, Degradation mechanism of azo dye C. I. reactive red 2 by iron powder reduction and photooxidation in aqueous solutions, Chemosphere, 41 (2000) 1233-1238 
[24] Joanna Grzechulska, Antoni Waldemar Morawski, Photocatalytic decomposition of azo-dye acid black 1 in water over modified titanium dioxide, Applied Catalysis B: Environmental, 36 (2002) 45-51
[25] Magallón-Cacho, L.; Pérez-Bueno, J.; Meas-Vong, Y.; Stremsdoerfer, G.; Espinoza-Beltrán, F. Weathering and Photodegradation of Cellulose. Surface \& Coatings Technology 206 (2011)1410-1415 